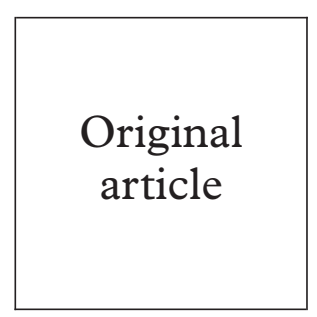

\title{
Clinical features of lichen sclerosus in men attending a department of genitourinary medicine
}

\author{
L Riddell, A Edwards, J Sherrard
}

Objectives: To characterise the clinical presentation and response to treatment of lichen sclerosus (LS) in men attending a department of genitourinary medicine.

Methods: A case note review of all men attending a GUM department over a 32 month period, who had been diagnosed as having LS.

Results: 66 men were seen with genital LS. The mean age at diagnosis was 36.5 years but symptoms had been present for up to 10 years before the diagnosis was made. 55 men underwent biopsy and the diagnosis was made histologically in 47 of these men. At the time of presentation $30 \%$ of men had no symptoms relating to their LS. All were treated with potent topical steroids and surgery was avoided in nearly all of them.

Conclusions: LS is not uncommon in men presenting to a GUM department, and is often asymptomatic. The disease responds well to potent topical steroids allowing the normal anatomy to be preserved in most individuals.

(Sex Transm Inf 2000;76:311-313)

Keywords: lichen sclerosus; men; genitourinary medicine clinics

\section{Introduction}

Lichen sclerosus (LS) is an inflammatory disease of the skin of undetermined aetiology. ${ }^{1}$ It can present at any age and, while initially thought to be much more common in females, it has become increasingly recognised in males. $^{23}$ The reported series are on symptomatic men presenting to surgeons, ${ }^{4-6}$ usually because of phimosis or urethral stricture secondary to their LS, or to dermatologists. ${ }^{2} 78$ There are few reports of the spectrum of clinical features of genital LS in men and those that there are look at small numbers of men..$^{2-7}$

Men with genital symptoms can self refer to departments of genitourinary medicine (GUM) and in recent years the clinic at Oxford has seen a number of men with lichen sclerosus. Recently the department has been involved in a study looking at HLA associations and susceptibility to autoimmune disease of men with LS. ${ }^{9}$ In view of the relative paucity of information on the clinical features of men with LS, in particular those with less severe disease, it was decided to review the clinical presentation, extent of disease, and outcome of treatment of men seen in a GUM department with LS.

\section{Department of Genitourinary Medicine, Radcliffe Infirmary, Oxford OX2 6HE \\ L Riddell \\ A Edwards \\ J Sherrard \\ Correspondence to: Dr Jackie Sherrard lynnriddell@yahoo.com}

Accepted for publication 20 April 2000

\section{Methods}

The case notes of all men, with a diagnosis of LS, seen in a department of GUM between January 1996 and September 1998 were reviewed. Data were collected on clinical features, relevant medical history, treatments used, and response to treatment. A unique diagnostic code is given to individuals with LS, for recording on the clinic's computerised data collection system, and this enabled patients to be easily identified.

\section{Results}

STUDY POPULATION

Between 1 January 1996 and 30 September 1998, 66 men with a diagnosis of LS attended the department of GUM at Oxford. In most cases the diagnosis had been made during the study period, but 27 men had been diagnosed with LS previously and were either attending for follow up for their LS or for other unrelated reasons, most commonly screening for sexually transmitted infections.

The mean age at diagnosis of LS was 36.5 years with a range of $20-73$ years. The mean age at development of symptoms related to LS was 34.3 years with a range of $11-65$ years. The mean age at development of signs attributable to LS was 32.0 years with a range of 11-66 years. Men had symptoms for many months and sometimes years before a diagnosis was made (table 1).

CLINICAL FINDINGS

Nearly $30 \%$ of the men did not complain of any symptoms relating to LS at the time of diagnosis, frequently attending the GUM department for other reasons and with the diagnosis being made when the genitals were examined. The most frequent symptoms complained of were a tight foreskin and difficulty in passing urine, but a range of other symptoms were experienced (table 2).

No man in this series had documented extragenital LS and in all men the genital

Table 1 Time from first symptoms to diagnosis of lichen sclerosus (LS) in 47 men with symptomatic disease

\begin{tabular}{lc}
\hline $\begin{array}{l}\text { Duration of symptoms before } \\
\text { diagnosis of } L S\end{array}$ & Number $(n=47)$ \\
\hline$<6$ months & $7(14.9 \%)$ \\
$6 / 12-2$ years & $18(38.3 \%)$ \\
$3-5$ years & $15(31.9 \%)$ \\
$6-10$ years & $4(8.5 \%)$ \\
$>10$ years & $3(6.4 \%)$ \\
\hline
\end{tabular}


Table 2 Symptoms complained of by men with lichen sclerosus

\begin{tabular}{lll}
\hline Symptom & $\begin{array}{l}\text { Number with } \\
\text { symptom }\end{array}$ & $\begin{array}{l}\text { \% of patients } \\
\text { with symptom } \\
(n=66)\end{array}$ \\
\hline None/not recorded & 19 & 28.8 \\
Tight foreskin & 17 & 25.8 \\
Difficulty passing urine & 13 & 19.7 \\
Itching & 12 & 18.2 \\
Painful erections & 9 & 13.6 \\
Soreness & 9 & 13.6 \\
Cracking/bleeding & 6 & 9.1 \\
Redness/rash & 5 & 7.6 \\
Torn/tight frenulum & 2 & 3.0 \\
Dysuria & 1 & 1.5 \\
\hline
\end{tabular}

Some patients complained of more than one symptom.

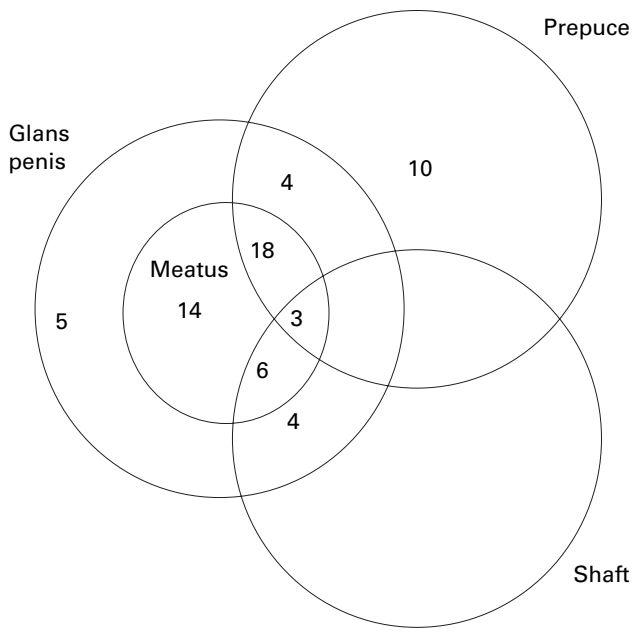

Figure 1 Patterns of disease involvement in 64 patients (not recorded in the other two men).

disease was confined to the penis. The site(s) affected was not documented in two of the 66 men and they are excluded in further analysis of the clinical findings. The most commonly affected sites were the meatus in $41(64.1 \%)$ men, although only 15 had meatal narrowing, and the prepuce in $35(54.7 \%)$ men. Thirteen men $(20.3 \%)$ had disease affecting the penile shaft, and the glans penis not including the meatus was affected in $13(20.3 \%)$ men. Six $(9 \%)$ of the men had been circumcised before their first attendance at the GUM department. Two had had the operation performed as infants, three as teenagers, all for "tight foreskins," and in one man the age at surgery was not recorded. All these men had meatal involvement and two additionally had disease on the glans penis. The patterns of disease involvement are shown in figure 1 .

The physical signs (table 3 ) varied from mild pallor to ulceration with petechiae and complications including meatal narrowing and phimosis.

HISTOLOGICAL DIAGNOSIS

Fifty three men underwent biopsy and the diagnosis of LS was proved histologically in 47 $(88.7 \%)$ of these men. In three specimens the histology was suggestive but not conclusive of LS, and histology in the other three showed only non-specific changes. Three men defaulted before a biopsy could be performed. In seven men with meatal disease only, a biopsy was not performed owing to difficulties in
Table 3 Signs on examination in the 64 men where signs were recorded

\begin{tabular}{lll}
\hline Signs & $\begin{array}{l}\text { Number of } \\
\text { men with sign }\end{array}$ & $\begin{array}{l}\text { \% of men with } \\
\text { sign }(n=64)\end{array}$ \\
\hline Pallor/atrophy & 47 & 73.4 \\
Meatal stricture & 15 & 23.4 \\
Telangectasia/petechiae & 12 & 18.8 \\
Tight foreskin & 9 & 14.1 \\
Ulcers & 9 & 14.1 \\
Fissures/cracking & 5 & 7.8 \\
Papular lesions & 2 & 1.6 \\
\hline
\end{tabular}

obtaining a sample. In three other men the diagnosis was made on clinical grounds and the reason for not performing a biopsy was not documented in the notes. There was no difference in the clinical presentation or response to treatment in those with histologically proved disease compared with those with a clinical diagnosis only.

GENITAL WART INFECTION

Six men had a history of previous genital wart infection, and one patient attended the clinic as a known contact of someone with genital warts.

TREATMENT OUTCOMES

Three men received no treatment, two of whom defaulted before biopsy and one who defaulted after biopsy.

The standard initial treatment was with clobetasol propionate $0.05 \%$ cream (Dermovate, Glaxo), a potent steroid, which patients were prescribed to use once or twice daily for up to 3 months. Fifty men have received treatment with Dermovate cream alone. Eight men defaulted from follow up shortly after initiating treatment with Dermovate; four of whom were seen at least once subsequently with improving disease. The mean duration of follow up of the remaining 42 men is 3.4 years with a range of 2 months to 10 years. At the last attendance six men had active disease, two of whom were newly diagnosed and four experiencing an exacerbation. The disease free periods in the four men experiencing an exacerbation were 2 , 5,6 , and 7 years respectively following a good initial response to treatment.

Circumcision was recommended only in cases when there was a tight phimosis that did not improve with Dermovate, although in several men the LS improved. Eight of the nine men with a tight phimosis at presentation subsequently underwent circumcision. These men have been followed up for 6 months to 11 years after surgery, and two men have experienced an exacerbation of the LS on the glans penis which has responded to Dermovate in both cases.

Men with meatal disease are treated with topical Dermovate, applied into the meatus using an ENT swab. Additionally five men required urethral dilatation for meatal stenosis. The duration of follow up in these five men is 6 months to 5 years and none has required a repeat dilatation. Three have inactive disease and two experience occasional flare ups which respond to a short course of topical steroid. 


\section{Discussion}

This is one of the largest reported series of men with genital lichen sclerosus. Unlike previous studies $^{2-8}$ a high proportion were asymptomatic at the time of diagnosis, and the diagnosis was made because of other reasons for presenting to a department of GUM. The extent of asymptomatic disease in this series would suggest the true prevalence of LS in men might be much higher than published work suggests. The opportunities for asymptomatic men to have a genital examination are few. Some of these men may not have developed symptoms. It is also possible that early diagnosis and treatment may have prevented them from developing severe symptoms in the future, possibly requiring surgery.

As in other studies, men at any age were affected and some had clearly had disease since childhood. It has been reported that LS is a frequent cause of true phimosis in boys and adolescents requiring circumcision. ${ }^{10}{ }^{11}$ It was 3 or more years after the onset of symptoms before the diagnosis was made in nearly half the men. This may reflect a general reluctance among men to seek advice for genital symptoms, but in some cases medical advice had been sought and the diagnosis not made. In generalist settings the diagnosis is uncommon and may not be recognised.

Extragenital lesions were not documented in this series and there were no lesions seen on the scrotum. In women with LS the risk of squamous cell carcinoma is put at $4-5 \%$, and in men there have been only anecdotal reports. ${ }^{12}$ We have seen no cases of malignancy to date, in men with LS. It may be that with more cases and longer follow up we will observe some cases. It has been suggested that other risk factors may be the cause of penile carcinoma seen in men with LS such as phimosis related hygiene problems and human papilloma virus infection. ${ }^{1}$ Six men in this series gave a history of genital wart infection and several had prolonged phimosis.

The majority of men in this series have responded to potent topical steroids as first line therapy; only $12 \%$ have required circumcision. This is in contrast with the general view that LS in men is primarily a surgical problem, unlike in women where first line therapy with potent topical steroids is well described. ${ }^{12-14}$ The symptoms experienced were varied and reflected the anatomical distribution of disease seen. The meatus was involved in nearly two thirds of the men, but only one third of these complained of difficulty in passing urine and meatotomy was required in only $12 \%$ of those with meatal disease. Circumcision is frequently carried out when patients present to urological services with LS. Our study suggests that at least $60 \%$ of men with phimosis will have concomitant meatal involvement. It would seem logical to treat all affected areas with Demovate initially for at least 6 weeks. In our view surgery should reserved for patients failing to respond to medical treatment.

This study suggests that genital LS is not uncommon in men of all ages attending departments of genitourinary medicine. The LS may be asymptomatic, but can cause a variety of symptoms. The diagnosis can be suspected following careful examination of the genital area, and confirmed by biopsy where affected skin can be sampled. As clinicians become familiar with the disease it may be that biopsy can be reserved for atypical lesions. Treatment with potent topical steroids is effective in most cases, and surgery is only needed in cases of tight phimosis or severe meatal stenosis. Where surgery is undertaken, most patients benefited from steroids either preoperatively or postoperatively. While most men remain under regular review, to date no malignancies have developed, although several men have other potential risk factors for carcinoma of the penis including genital papilloma virus infection, or chronic phimosis causing hygiene problems.

Contributors: LR collected and analysed the data; AE helped to prepare the manuscript; JS was involved in the study design and management and preparation of the manuscript.

1 Meffert JJ, Davis BM, Grimwood RE. Lichen sclerosus. $\mathcal{F}$ Am Acad Dermatol 1995;32:393-416.

2 Meyrick Thomas RH, Ridley CM, Black MM. Clinical features and therapy of lichen sclerosus et atrophicus affecting tures and therapy of lichen sclerosus et atropt
males. Clin Exp Dermatol 1987;12:126-8.

3 Crow KD, Ellis J, Wynne EJC. Lichen sclerosus et atrophicus of the penis. A comparison of topical and surgical treatment. Br f Dermatol 1980;103:(Suppl 18) 17 .

4 Staff WG. Urethral involvement in balanitis xerotica obliterans. Br F Urol 1970;42:234-9.

5 Bainbridge DR, Whitacker RH, Shepheard BGF. Balanitis xerotica obliterans and urinary obstruction. $\mathrm{Br} f$ Urol 1971;43:487-91.

6 Campus GV, Ena P, Scuderi N. Surgical treatment of balanitis xerotica obliterans. Plastic Reconstruct Surg 1984; 73:652-7.

7 Wallace HJ. Lichen sclerosus et atrophicus. Trans St fohn's Hosp Dermatol Soc 1971;57:9-30.

8 Ledwig PA, Weigand DA. Late circumcision and lichen sclerosus et atrophicus of the penis. F Am Acad Dermatol 1989;20:211-14.

9 Azurdia RM, Luzzi GA, Byren I, et al. Lichen sclerosus in adult men: a study of HLA associations and susceptibility to autoimmune disease. Br f Dermatol 1999;140:79-83.

10 Chalmers RTG, Burton PA, Bennett RF, et al. Lichen sclerosus et atrophicus: a common and distinctive cause of phirosus et atrophicus: a common and distinctive cause
mosis in boys. Arch Dermatol 1984;120:1025-7.

11 Garat JM, Chechile G, Algaba F, et al. Balanitis xerotica obliterans in children. F Urol 1986;136:436-7.

12 Powell JJ, Wojnarowska F. Lichen sclerosus. Lancet 1999; 353:1777-83.

13 Friedman $\mathrm{M}$, Weissman A, Kerner $\mathrm{H}$, et al. Vulvar lichen sclerosus treated with super potent topical corticosteroid clobetasol proprionate $0.05 \%$ ). Cervix and the Lower Female Genital Tract 1994;12:21-4.

14 Dalziel KL, Wojnarowska F. Long-term control of vulval lichen sclerosus after treatment with a potent topical steroid cream. F Reprod Med 1993;38:25-7. 